\title{
Decentralisation of Health Services in Fiji: A Decision Space Analysis
}

\author{
Jalal Mohammed*, Nicola North, Toni Ashton
}

\begin{abstract}
Background: Decentralisation aims to bring services closer to the community and has been advocated in the health sector to improve quality, access and equity, and to empower local agencies, increase innovation and efficiency and bring healthcare and decision-making as close as possible to where people live and work. Fiji has attempted two approaches to decentralisation. The current approach reflects a model of deconcentration of outpatient services from the tertiary level hospital to the peripheral health centres in the Suva subdivision. Methods: Using a modified decision space approach developed by Bossert, this study measures decision space created in five broad categories (finance, service organisation, human resources, access rules, and governance rules) within the decentralised services.

Results: Fiji's centrally managed historical-based allocation of financial resources and management of human resources resulted in no decision space for decentralised agents. Narrow decision space was created in the service organisation category where, with limited decision space created over access rules, Fiji has seen greater usage of its decentralised health centres. There remains limited decision space in governance.

Conclusion: The current wave of decentralisation reveals that, whilst the workload has shifted from the tertiary hospital to the peripheral health centres, it has been accompanied by limited transfer of administrative authority, suggesting that Fijis deconcentration reflects the transfer of workload only with decision-making in the five functional areas remaining largely centralised. As such, the benefits of decentralisation for users and providers are likely to be limited.

Keywords: Decentralisation, Health Reform, Decision Space, Access to Healthcare, Principal Agent Approach, Fiji

Copyright: (c) 2016 by Kerman University of Medical Sciences

Citation: Mohammed J, North N, Ashton T. Decentralisation of health services in Fiji: a decision space analysis. Int J Health Policy Manag. 2016;5(3):173-181. doi:10.15171/ijhpm.2015.199
\end{abstract}

\section{Article History:}

Received: 22 May 2015 Accepted: 6 November 2015 ePublished: 15 November 2015

\section{*Correspondence to:}

Jalal Mohammed

Email: j.mohammed@auckland.ac.nz

\section{Key Messages}

Implications for policy makers

- The potential benefits of decentralisation, such as closer community involvement in services, may be limited when decision space is not created. It is important for policy-makers to give attention not only to transfer of workload, but also to localised decision-making.

- Localised decision space needs to be created in terms of finance, service organisation, human resources, access rules, and governance rules to realise the benefits of decentralisation.

Implications for public

This study provides the public with an understanding of the decentralisation policy in Fiji that is yet to be sufficiently evaluated. Public understanding of the policy could encourage support for ongoing reforms in the country.

\section{Background}

Fundamental changes to health systems and the delivery of healthcare have been advocated globally. ${ }^{1,2}$ This push to reform has been particularly evident in developing countries where decentralisation has been promoted as one way to improve the delivery of health services and its outcomes. ${ }^{3}$ Fiji is no exception, with two waves of health sector decentralisation having taken place since 1999. However, there has been limited evaluation of these reforms. This paper examines the decentralisation process being implemented in the Suva subdivision since 2009, using the decision space analytical framework developed by Bossert. ${ }^{4}$ In doing so the aim of this paper is not to evaluate the impact of the reforms on outcomes, but to assess the extent to which different functions have actually been decentralised.

\section{Approaches to Decentralisation}

Decentralisation has been central to health services development and reform in developing countries, aiming to encourage community involvement and increase health services' responsiveness to the community. This reflects the Alma Ata Declaration in 1979 which highlighted the importance of bringing healthcare and decision-making as close as possible to where people live and work. ${ }^{5}$ Whilst decentralisation of health services has been widely promoted since the 1970s, how the concept is defined lacks conceptual clarity. ${ }^{6,7}$ There is, however, an emerging consensus that decentralisation broadly refers to the transfer of authority 
to manage, plan and make decisions, from the central government to agencies and actors at lower levels. ${ }^{1,7-11}$

Decentralisation, in its many forms, seeks to promote a more effective and efficient system aimed at rectifying a topdown bureaucratic structure and improving government responsiveness to the public. . $8,10,12$ Among its many promises, decentralisation aims to bring services closer to people, ${ }^{8,10,13}$ improve access to services, ${ }^{1,8}$ allow for community participation, ${ }^{12,14}$ improve employee morale and turnover ${ }^{15}$ and place particular emphasis on improving quality, access and equity, empowering local governments and increasing innovation and efficiency. ${ }^{8-10}$ However, decentralisation is difficult to implement. As such the intended benefits may not necessarily be achieved and may not result in greater community participation, access for all communities and greater equity. ${ }^{2,7,8}$

Although there is some agreement on the expected benefits of decentralisation, the ways in which it has been implemented has varied across countries. ${ }^{1}$ Decentralisation in health systems may be functional or geographical in nature. ${ }^{1}$ Functional decentralisation involves the transfer of specific responsibilities from the central agency at the national level to specialised agencies at national or subnational levels. Geographical decentralisation involves the transfer of wideranging responsibilities from the central agency to subnational organisations that have precise geographical and political boundaries. $^{2,16}$ With that understanding in mind, three forms of decentralisation (deconcentration, delegation, and devolution) were proposed by Rondinelli. ${ }^{2}$ These were further refined by Mills ${ }^{16}$ to include a fourth form (privatisation). However, individual country experiences of decentralisation seldom fit precisely into one of the types mentioned above. Countries experiment with varying degrees and approaches to decentralisation and may use a combination of models to meet their needs and to achieve their particular objectives. ${ }^{1}$ Deconcentration is the least imposing form of decentralisation. It involves moving some workload from the central national ministry or agency to subnational levels. ${ }^{2}$ This shifting of workload may also involve the transfer of administrative authority, but not political authority, to the subnational levels. ${ }^{16}$ Where there is a shifting of authority to the lower levels, deconcentration takes one of two forms: field administration and local administration. ${ }^{2}$ The former involves the transfer of decision-making to staff at lower levels, thereby allowing the local health services to be responsive to local needs by engaging local staff in planning and decision-making functions. Local administration, on the other hand, is where subnational levels are agents of a central office and all local functions are undertaken through the technical supervision and control of a central office.

Delegation involves the transfer of decision-making as well as administrative authority for well-defined functions to agencies that are not part of the central ministry but over which the ministry retains some level of indirect control. ${ }^{2}$ These agencies have an independent status that is established under law and a management board or board of trustees holds management authority and decision-making responsibilities. ${ }^{16}$ Devolution, on the other hand, involves the creation or reinforcement of subnational levels of government that then undertake a fixed set of functions from the central ministry.
These independent agencies have a clear legal status with geographically-defined boundaries as well as having the statutory authority to raise revenue and determine their expenditure.

Privatisation is the most extreme form of decentralisation. It involves the transfer of functions that would normally have been performed by the central ministry to organisations it does not own, and which are independent and outside the control of the central ministry. Whilst the central ministry does not control the organisation, it may influence its behaviour through government regulations and financial incentives and disincentives. ${ }^{1}$

\section{Using Decision-Making as a Measure of Decentralisation}

Bossert ${ }^{4}$ developed an approach to measure the degree of decentralisation based on the transfer of decision-making. The decision space tool proposes a set of indicators which can be used to map decision space under the four approaches to decentralisation. As a tool, it has been used to highlight the degree of choice exercised by decentralised agencies over different organisational functions in several developing countries. $^{4,13,14,17,18}$ This tool is based on a modified principalagent approach developed by economists to measure relationships within a defined 'principal' and 'agent' setting. ${ }^{19}$ The principal-agent approach conceptualises a 'principal' with specific objectives, and 'agents' who are engaged to achieve those objectives. The benefit of this approach is that it allows for the examination of the dynamic and evolving relationship between the central office (ie, the principal) and peripheral agents following decentralisation. Bossert's decision space tool is used in this study to gain insights into the current decentralisation approach in Fiji.

\section{Fiji's Approach to Decentralisation}

The Ministry of Health $(\mathrm{MoH})$ is the principal healthcare funder and provider in Fiji. The delivery of healthcare to its 887000 people is challenging in a country that comprises 332 islands spread over 1.3 million square kilometres of the South Pacific Ocean. ${ }^{20}$ Health services are delivered through three geographical divisions: the jointly administered Central and Eastern Divisions, Western Division and Northern Division, each having several subdivisions. ${ }^{21}$ Divisional hospitals provide tertiary and secondary level care whilst subdivisional hospitals provide primary and limited secondary care. Each subdivision has several health centres providing primary care, intended as the first point of contact for most users, and the basic unit in the health services infrastructure. Depending on their size and level, health centres are staffed by medical officers, nurses, midwives, and ancillary staff.

Successive governments have called for a more responsive healthcare system that makes healthcare accessible to all its citizens through strengthened divisional structures and improved community-based services, and by addressing community dissatisfaction with health services. ${ }^{22-29}$ Reviews carried out since 1979 highlighted the need to decentralise Fiji's healthcare system in order to improve service delivery. They concluded that the $\mathrm{MoH}$ did not delegate responsibility, authority and planning to the regional divisions, which resulted in poor morale, high turnover, high number of staff transfers, inadequate staff numbers, and shortages of drugs 
at health facilities. The reviews also recommended that measures be taken to encourage those patients self-referring to Suva's main tertiary hospital (Colonial War Memorial [CWM] Hospital) to instead attend outpatient clinics at the peripheral health centres and at the subdivisional hospitals nearest to their homes and places of employment. ${ }^{22-25,30,31}$ In response, Fiji has experimented with two waves of health sector decentralisation, separated by a brief but abandoned attempt at re-centralisation, detailed below. The first wave of decentralisation (1999-2004) aimed at devolving the health system geographically, and is considered the most ambitious of the two waves of reforms. However, its lack of acceptance by many in the health sector hindered implementation, and coupled with continuing political instability in Fiji, resulted in re-centralisation in 2008. Following the Fijian Government's change in policy and a renewed focus to improve health services' accessibility to the general public, ${ }^{26,27}$ the second wave of decentralisation began in 2009. These reforms are detailed below to provide context for the study.

\section{Health Sector Reform (1999-2004)}

In 1999 the Minister for Health initiated the Fiji Health Management Reform Project, with the aim of improving healthcare and health outcomes and improving decisionmaking by bringing it as close as possible to the point of implementation. ${ }^{32,33}$ The reform also aimed to improve customer-focused service delivery at primary, secondary, and tertiary levels. ${ }^{33,34}$

With the support of AUSAid funding and expertise, the reform project was aimed at devolving Fiji's centralised health system after a legacy of British rule. ${ }^{35}$ Prior to decentralisation, there was a central ministry with four administrative divisions and the reform project proposed the creation and strengthening of divisional levels within the $\mathrm{MoH}$. As a result, the central office was strengthened and three geographical divisions were created to focus on health service delivery. ${ }^{33}$ The roles of the central office and the geographical divisions were delineated, with the central office having four areas of operation to support its functions of (1) policy development, (2) national health service planning, (3) monitoring and evaluation, and (4) legislative and regulatory compliance. This allowed the central office to provide technical and supervisory support to the geographical divisions responsible for the delivery of health services in their respective areas. Proposed legislation would have enabled those divisional structures to become corporate legal entities to be responsible for their own planning and control systems and for quality management. The legislation would have also allowed them to enter into contracts, manage their own budgets and human resources, and have powers to delegate functions to organisations outside the ministry. ${ }^{36}$ This would have allowed a truly devolved structure to emerge. However, the proposed legislation was never enacted, and with waning interest resulting from four changes of government in the 5-year implementation period for the decentralisation project, reform was only partially implemented.

\section{Roll-back of Health Reform (2008)}

In 2005, with AUSAid funding extinguished and health sector reform incomplete, no further work was carried out from 2005 until 2008. In February 2008, many of the decentralisation initiatives carried out under the first wave were reversed. ${ }^{37}$ What has popularly been termed as the 'rollback of health sector reform,' meant that changes made to the $\mathrm{MoH}$ during the reform period were abandoned and the $\mathrm{MoH}$ reverted to a centralised system. Political instability and changes of governments, along with a lack of implementation of the reforms and decentralisation objectives having not been achieved, have widely been seen as the reasons for the 'roll-back.'38

\section{Decentralisation of Health Services (2009 to Present)}

Ten years after the first wave, the second wave of decentralisation was initiated in March 2009, with a more modest aim of improving access to health services in the Suva subdivision only. ${ }^{39}$ Heeding calls from the Government to improve 'physical and financial access to good-quality health services, ${ }^{26}$ the $\mathrm{MoH}$ initiated a pilot process of deconcentrating outpatient services from the divisional hospital in the Suva subdivision to six health centres located within its geographical boundaries, which serve a quarter of Fiji's population..$^{21,26,27}$ As a pilot project, the deconcentration was only intended for the Suva subdivision. This involved strengthening the health centres and designating the CWM Hospital as a referral service that the general population in the Suva subdivision could access only by being referred..$^{40}$ Strengthening of these six health centres took place over a 2 -year period starting from March 2009. Hours of operation at the six health centres increased from 8 to 16 hours per day in weekdays (from 8 AM-4:30 PM to 6:30 AM-10 PM) and began to open in the weekend for 8 hours per day from 8 AM-4 PM. ${ }^{41-43}$ In addition service hours at the health centres were extended, and services provided at these health centres were improved and upgraded through a boost to human resources, infrastructure, consumables and medications, equipment, transport and administration. ${ }^{43-46}$ The CWM Hospital subsequently stopped providing adult outpatient services from the end of February 2011. With decentralisation in the Central Division deemed a success, the $\mathrm{MoH}$ has proposed a roll-out of decentralisation policy to the Northern and Western Divisions. ${ }^{39,40}$ While deemed a success, there is no evidence of the impacts of the decentralisation process on the different functions of the $\mathrm{MoH}$. This study attempts to fill that gap by examining the extent to which various functions have actually been decentralised.

\section{Methods}

This desktop analysis is based on available documentary sources, studies, reviews, technical reports, policy documents, and position papers covering the period 1979 to 2014. This allowed for comparisons to be made between the first and second reforms. However, the primary focus of the analysis is on the period after 2008, following roll-back of the first wave of reforms and the second decentralisation process in 2009. All documents collected were in the English language, this being the official language of Fiji. Requests for unpublished studies, opinion papers, and position papers were made through personal communications with Fijis $\mathrm{MoH}$ with access granted as part of the ethics approval.

Incomplete documents were excluded and the remainder 
sorted by decentralisation period. The contents were then analysed by examining the implications of decentralisation on finance, service organisation, human resources, access rules and governance as outlined in Table 1.

The decision space framework has been employed in a number of settings to analyse decentralisation including Chile, Colombia, Guatemala, Uganda, Zambia, Ghana, Philippines, and Pakistan. ${ }^{14,17,18,47-49}$ The decision space framework comprises five categories of functions: finance, service organisation, human resources, access rules and governance, as shown in Table $1 ., 14,17,48$ The framework examines both what is allowed by the central authority and what the agency actually exercises following decentralisation (whether through deconcentration, delegation, devolution or privatisation). The approach estimates the changes to the decision space within each of these functions and classifies the change as being narrow, moderate, or wide.

A modified decision space approach for Fiji was used for this study. This framework was chosen for its applicability to developing countries and because it is based on the principal agent approach which forms the underlying basis for Fiji's current wave of decentralisation. The decision space framework defines the choice allowed by the principal to the agent. However, a notable criticism of this tool is that it is a formal map of the decision space which may not reflect the actual range of decisions that the agent may have in countries where laws are not enforced or easily violated by the agent. In applying Bossert's framework for mapping decision space to this study, the 'principal' refers to the $\mathrm{MoH}$ central office and the 'agents' refer to the six decentralised health centres in the Suva subdivision. Other notable government agencies that influence decision-making that will be alluded to in the following discussions are the Public Services Commission (PSC) and the Ministry of Finance (MoF).

The mapping used the same broad categories identified by Bossert; however, only functions applicable to Fiji's public health sector were used to guide this analysis of decision space in Fiji. For example, Fiji has no insurance plans for the public health services, thus this was removed when creating the decision space map. An additional measure of 'no choice' was added to the range of choices for Fiji's decision space map to indicate where agents had no choice for a particular function.

\section{Results}

An examination of the current wave of decentralisation reveals that, whilst the workload has shifted from the CWM Hospital to the peripheral health centres (refer to Table 2), it has been accompanied by only limited transfer of administrative authority, suggesting that Fiji's reforms reflect limited deconcentration in the form of transfer of workload. Each indicator and function is described in detail in the following sections.

\section{Finance}

In Fiji, the MoF is responsible for public sector funding which is released to the respective ministries through a yearly budget allocation. The process involves consultation with the various central offices of each ministry. In the case of the $\mathrm{MoH}$, each of the three geographical divisions devise a divisional business plan in consultation with the central office which, once approved, provides a basis for the $\mathrm{MoH}$ budgetary request from the MoF. The Central Office uses actual expenditure incurred over the past years as a means of determining divisional allocations. Subdivisions draw their respective budgets from their divisions. Health centres have no specific budgetary allocation and need to rely on their respective subdivisions.

Whilst the divisions, subdivisions and health centres have some input into their budgetary allocation, it is largely centrally controlled. The principal has wider powers compared to the agent in determining the sources of revenue. Decentralisation shifted outpatient services to health centres in the Suva subdivision in 2009. An examination of total government health expenditure (TGHE) over the second

Table 1. Bossert's Framework for Mapping Decision Space

\begin{tabular}{|c|c|c|}
\hline Category & Function & Indicators \\
\hline \multicolumn{3}{|l|}{ Finance } \\
\hline & Sources of revenue & Intergovernmental transfers as a \% of total health spending \\
\hline & Income from fees and contracts & Range of prices local authorities are allowed to choose \\
\hline & Contracts & Number of models allowed \\
\hline \multicolumn{3}{|c|}{ Service Organisation } \\
\hline & Insurance plans & Choice of how to design insurance plans \\
\hline & Payment mechanisms & Choice of how providers will be paid \\
\hline & Required programs & Specificity of norms for local programs \\
\hline \multicolumn{3}{|c|}{ Human Resources } \\
\hline & Salaries & Choice of salary range \\
\hline & Contracts & Contracting of non-permanent staff \\
\hline \multicolumn{3}{|c|}{ Access Rules } \\
\hline & Targeting & Defining priority populations \\
\hline \multicolumn{3}{|c|}{ Governance Rules } \\
\hline & Facility boards & Size and composition of boards \\
\hline & Health offices & Size and composition of local offices \\
\hline & Community participation & Size, number, composition, and role of community participation \\
\hline
\end{tabular}


Table 2. Daily Workload at Health Facilities Before and After Decentralisation

\begin{tabular}{|c|c|c|c|c|c|c|}
\hline \multirow[b]{2}{*}{ Health Facility } & \multicolumn{2}{|c|}{$2010^{a}$} & \multicolumn{2}{|c|}{2011 (February) $^{b}$} & \multicolumn{2}{|c|}{2011 (March) $^{c}$} \\
\hline & $\begin{array}{c}\text { Average Daily } \\
\text { Workload }\end{array}$ & $\begin{array}{c}\text { Average Time Spent } \\
\text { per User }\end{array}$ & $\begin{array}{c}\text { Average Daily } \\
\text { Workload }\end{array}$ & $\begin{array}{c}\text { Average Time Spent } \\
\text { per User }\end{array}$ & $\begin{array}{c}\text { Average Daily } \\
\text { Workload }\end{array}$ & $\begin{array}{c}\text { Average Time Spent } \\
\text { per User }\end{array}$ \\
\hline Lami Health Centre & 36 & $8.3 \mathrm{~min}$ & 100 & $8.6 \mathrm{~min}$ & 123 & $6.7 \mathrm{~min}$ \\
\hline Samabula Health Centre & 45 & $10.0 \mathrm{~min}$ & 108 & $7.5 \mathrm{~min}$ & 149 & $5.0 \mathrm{~min}$ \\
\hline Raiwaqa Health Centre ${ }^{d}$ & 24 & $33.0 \mathrm{~min}$ & - & - & 197 & $4.3 \mathrm{~min}$ \\
\hline Nuffield Health Centre & 36 & $12.3 \mathrm{~min}$ & 101 & $8.0 \mathrm{~min}$ & 125 & $6.7 \mathrm{~min}$ \\
\hline Valelevu Health Centre & 52 & $4.4 \mathrm{~min}$ & 254 & $3.0 \mathrm{~min}$ & 299 & $2.8 \mathrm{~min}$ \\
\hline Makoi Health Centre & 43 & $6.8 \mathrm{~min}$ & 222 & $4.6 \mathrm{~min}$ & 255 & $3.3 \mathrm{~min}$ \\
\hline CWM - GOPD & 31 & $15.0 \mathrm{~min}$ & 39 & $12.0 \mathrm{~min}$ & - & - \\
\hline$C W M-A \& E^{f}$ & 23 & $20.0 \mathrm{~min}$ & 24 & $20.0 \mathrm{~min}$ & 21 & $20.0 \mathrm{~min}$ \\
\hline
\end{tabular}

Abbreviations: GOPD, General Outpatient Department; CWM, Colonial War Memorial Hospital; A\&E, Accident and Emergency.

${ }^{a}$ Denotes averages for the 2010 period.

${ }^{b}$ Denotes averages for February 2011 prior to closure of GOPD services at CWM Hospital.

${ }^{c}$ Denotes averages for March 2011 following closure of GOPD services at CWM Hospital.

${ }^{\mathrm{d}}$ Ministry of Health (MoH) reports indicate not data was supplied by Raiwaqa Health Centre for February 2011.

${ }^{f}$ CWM A\&E Department provides GOPD services after closure of Health Centres at 10 PM. Represents Night Shift (10 PM to 7 AM) data only.

decentralisation period reveals the percentage allocated nationally to outpatient services declined from $27.3 \%$ and $27.5 \%$ [ $\$ 41.6$ million and $\$ 42.0$ million] of TGHE in 2009 and 2010 respectively to $19.4 \%$ and $19.6 \%$ [ $\$ 27.6$ million and $\$ 30.1$ million] of TGHE in 2011 and 2012. ${ }^{50-52}$ Interestingly, the percentage of TGHE allocated to ambulatory care providers who are the focus of decentralisation, also declined from 9.4\% and $11.5 \%$ [ $\$ 14.3$ million and $\$ 17.6$ million] in 2009 and 2010 to $5.7 \%$ and $7.2 \%$ [ $\$ 8.2$ million to $\$ 11.1$ million] in 2011 and 2012. Hospitals continued to be allocated the majority of TGHE despite a transfer of services from the hospital to the health centres, although a slight decline can be seen from $77.2 \%$ and $74.6 \%$ [ $\$ 117.9$ million and $\$ 114.1$ million] of TGHE in 2009 and 2010 respectively to $73.2 \%$ and $68.2 \%$ [ $\$ 104.4$ million and $\$ 105.8$ million] of TGHE in 2011 and 2012. The extensive nature of devolution in the first wave of decentralisation could be a factor in the differences in financial allocation between the two decentralisation periods; however, this requires further investigation.

It is important to note that the expenditure figures for outpatient services quoted above apply to the total allocation of funds to outpatient services countrywide, and not specifically to the services that are being decentralised in the Suva subdivision. With no specific recorded budgetary allocation to the health centres in the Suva subdivision, the recording reflects a divisional breakdown. The principal's allocation to the central division health centres (of which Suva is one of five subdivisions), was $\$ 6.4$ million in 2009, $\$ 7.9$ million in 2010, \$2.4 million in 2011, and \$3.9 million in 2012. With decentralisation shifting workload from the divisional hospital to the health centres, an increase in the funding allocated to health centres would have been expected, not the reduction in allocations to the health centres that is reported. This decline is consistent with a decline in overall spending on outpatient services nationally, however.

Turning now to the allocation of expenditure, an examination reveals that the health centres have little decision space over the funding earmarked for them by the central office. The subdivisions, through their respective divisions, submit business plans which outline activities for the next year. These activities are linked to the strategic plan of the $\mathrm{MoH}$, government strategic vision and international obligations signed by the government. ${ }^{26,27,53,54}$ The divisional business plans guide the central office in the allocation of expenditure for health centres which have little scope to decide on its use. The recent decentralisation process has seen specific expenditures marked for health centres, specifically for the upgrading and maintenance of health centres and investment in equipment for health centres ${ }^{55-57}$; these funds must be used as earmarked.

The fee that can be charged by the decentralised health centres is determined by the Public Hospitals and Dispensaries Act. This legislation narrows the decision space of the agent by determining when they can charge fees and how much they can charge. As part of the government's initiative to provide universal healthcare to the citizens of Fiji, the health centres cannot charge fees to patients who self-refer to health centres. They can only charge set fees to patients who have been referred to public health services from a private service and patients who are not citizens of Fiji. ${ }^{58,59}$ However, the Act does allow for discretionary powers by the medical officer to waive any fees prescribed in the Act.

\section{Service Organisation}

Decentralisation of outpatient services did not flow through to increased health centre autonomy which is defined by law through the Public Hospitals and Dispensaries Act. The legislation gives some discretionary powers to the health centres in its normal day to day functions, vested in the medical officer in-charge of the health centre and gives the medical officer discretionary powers to treat patients. ${ }^{58,60}$ Other decisions are made in consultation with the subdivisional and divisional medical officers. The medical officer-in-charge having leeway in day-to-day operations of the health centre has resulted in variances in how service delivery is organised for walk-in users.

Health centres are classified according to the size of the population that they serve, and their location and distance from the referral hospital. A higher ranking (Level A being the highest and Level $\mathrm{C}$ being the lowest) ensures a higher quota of drugs and supplies in more regular frequency. Following decentralisation, the level of each health centre in the Suva subdivision increased (leaving no Level C health centre). This resulted in increased quota and frequency of 
supplies, but without increased autonomy, relegating them to deconcentrated entities without administrative authority. The central office sets priorities at a national level and allows the divisional levels some autonomy in achieving them. The central office works with divisional medical officers to ensure that divisional priorities are aligned with those at national level. ${ }^{53,54,61}$ Similar health programmes are seen across the decentralised health centres, reflecting centralised priority setting. However, health centres have some flexibility in offering programmes above the basic package required by the central office. The ranking of the health centre also determines the services delivered there, with higher ranked health centres being able to deliver more services, specifically more diagnostic and ancillary services, in addition to having higher allocations of supplies and drugs from the central office.

\section{Human Resources}

Creating decision space in the management of human resources is difficult in Fiji due to the high degree of centralisation of the civil services. The civil services are managed by the PSC with little or no control by the respective ministries. The PSC governs all aspects of human resources from determining the requirements of each ministry, determining the number of establishments, selection, setting salaries, appointment, training, appraisal, promotion, and discipline. ${ }^{62-64}$

For a brief period during the first wave of reform, the PSC delegated authority to the $\mathrm{MoH}$ to manage its own human resources as part of wider government reforms. However, this delegation was revoked following a change in government. ${ }^{37}$ No attempt to delegate such powers was made in the current decentralisation process, with contracting of permanent and non-permanent staff, increasing of staff numbers, determination of salary range and the ability to hire and fire remaining vested outside the powers of the agent and central office.

\section{Access Rules}

Access rules that determine the health programmes delivered by health centres to targeted populations are determined by a centrally defined package of health services. This package is guided by the strategic vision of the Fijian government, as well as its international obligations and prevailing health trends in the divisions. ${ }^{26,27,54,61}$ The central office requires that the health centres deliver the following package of health services: communicable and non-communicable disease services, family planning, maternal and child health and mental health services. Being centrally determined, this package is fairly consistent across the different health centres with centrally defined priority populations. Each health centre has some flexibility in adding to this list based on the needs of the populations that they cater to. The health centres also have flexibility in referring users to other services in cases where they do not have adequate resources to offer treatment. Whilst each health centre's ability to offer treatment varies, referral activity between health centres is not high, but there is a notable number of referrals from the health centres to the divisional hospital.
Governance Rules

Local governance and community participation have long been advocated as part of decentralisation in Fiji. ${ }^{31}$ The current deconcentration model of decentralisation provides some mechanisms for local governance although the governance structure is largely centralised. Each health centre has a 'board of visitors,' which has limited influence over some decisions. The Minister for Health, not local communities or agents, appoints members of the board, and these members are accountable to the Minister. Legislation empowers the board of visitors decision space over maintenance and repair of the health centres, and for ensuring that the health facility is well-equipped and has the necessary technology to deliver quality care. ${ }^{59}$ This gives the board of visitors some degree of influence over the decisions that are made at each health centre. The legislation also empowers the board of visitors to partner with private bodies to fulfil any of its functions.

Community participation in local health institutions is limited. Community health workers are involved in the delivery of health services, but their ability to influence the system based on this interaction with the communities is limited. Zone nurses based at each health centre form a key link between the health centre and the community in the provision of health services. They are often the first point of contact for communities and periodically deliver basic health services to communities within the catchment of the health centre. However, this link does not translate to increased community participation in the health centre. Other than through the membership of the board of visitors, there is no provision to have the community participate in the health facilities.

Table 3 summarises decision space in the Suva subdivision of Fiji, where decentralisation (involving a transfer of workload) has been initiated.

\section{Discussion and Conclusion}

Decentralisation is advocated as a way to improve the efficiency of delivery of health services and their responsiveness to community needs. In developing countries, decentralisation is also seen as a means to improve access to healthcare. However, to realise these benefits, a localised decision space needs to be created in terms of finance, service organisation, human resources, access rules, and governance rules.

This analysis shows that Fiji's current decentralisation process involves little more than the transfer of workload for ambulatory care from hospital to health centre. In the case of the Fijian health system, deconcentration is the form of decentralisation used and this has created limited decision space for the health centres to which workload has been transferred. It remains unclear whether the Government intends to transfer authority to these health centres.

A critical question is whether such limited decentralisation can produce the intended benefits. The decision space map shows that for finance, the current decentralisation process neither allows for the health centres to source their own revenue nor determine their expenditures. With Fiji's system of national health accounts being in its infancy, little or no financial information exists at the health centre level. Historical allocation of resources means that there is an inequitable distribution of financial resources in 
Table 3. Decision Space of Fiji's Decentralised Suva Subdivision

\begin{tabular}{|c|c|c|c|c|}
\hline \multirow{2}{*}{ Functions } & \multicolumn{4}{|c|}{ Range of Choice } \\
\hline & No Choice & Narrow & Moderate & Wide \\
\hline \multicolumn{5}{|l|}{ Finance } \\
\hline Sources of revenue & Determined by $\mathrm{MoH}$ central office & - & - & - \\
\hline Allocation of expenditure & $\begin{array}{l}\text { High percentage earmarked by } \mathrm{MoH} \text { in collaboration } \\
\text { with MoF }\end{array}$ & - & - & - \\
\hline Income from fees & No choice - determined by legislation & - & - & - \\
\hline \multicolumn{5}{|l|}{ Service Organisation } \\
\hline Health centre autonomy & Defined by law & - & - & - \\
\hline Required programs & $\begin{array}{l}\text { Basic package of programs defined by } \mathrm{MoH} \text { central } \\
\text { office }\end{array}$ & $\begin{array}{l}\text { Flexibility to offer programs above the basic } \\
\text { package, based on their resource }\end{array}$ & - & - \\
\hline \multicolumn{5}{|l|}{ Human Resources } \\
\hline Salaries & None - defined by PSC & - & - & - \\
\hline Contracts & None - determined by PSC regulations & - & - & - \\
\hline Civil service & Determined by PSC & - & - & - \\
\hline \multicolumn{5}{|l|}{ Access Rules } \\
\hline Targeting & Centrally defined priority populations & $\begin{array}{l}\text { Flexibility to add above the centrally defined } \\
\text { priority populations }\end{array}$ & - & - \\
\hline \multicolumn{5}{|l|}{ Governance Rules } \\
\hline Facility boards & Defined by legislation & - & - & - \\
\hline Community participation & - & Limited & - & - \\
\hline
\end{tabular}

Abbreviations: MoH, Ministry of Health; MoF, Ministry of Finance; PSC, Public Services Commission.

response to varying demands placed on each health centre. Financial autonomy has generally resulted in benefits for health systems $s^{14,17,49}$ and the decentralisation of the finance function can contribute to a more equitable utilisation of health services. ${ }^{18}$ However, this is unlikely to be realised in Fiji's current deconcentration approach. Calls made by health workers for population-based allocation of finances seem to go unanswered. Where population-based allocation does occur, it is in the allocation of pharmaceutical and consumable resources. However, the effectiveness of this allocation is undermined by high rates of internal migration into the Suva subdivision. ${ }^{65-67}$ Persistent shortages of pharmaceutical and consumable resources have been reported at these health centres since decentralisation (deconcentration) began. ${ }^{68}$ With deconcentration only applied to the Suva subdivision, an important question is whether local discretion in the finance function would bring benefits in equity, efficiency, and quality of healthcare.

The decision space function of service organisation is also limited in how services are organised at the health centre level. Although health centre autonomy is defined by law, and the medical officer-in-charge has some leeway in dayto-day operations of the health centre (resulting in variation in service delivery organisation for walk-in users), the package of programmes to be delivered at each health centre is prescribed by the central office. Whether decentralisation of service planning and organisation would better address variations in needs of local health centre populations is an important question that must be examined further.

The health centres and, for that matter, the central office, have little or no control over human resource management. This has a major impact on local decision space created. ${ }^{17} \mathrm{~A}$ consistent shortage of health professionals over the years, ${ }^{69,70}$ coupled with an inability to fill established posts, begs the question of whether these health centres are in a position to realise the benefits of decentralisation.

The importance of governance rules and popular participation are integral to creating decision space. Plagued by coup d'états and changes of governments, there has been limited popular participation in the health sector. The current decentralisation of health services has not flowed through to expanded popular participation. Whether popular participation would result in a more effective health system in an ethnically fragmented society, or further perpetuate ethnic divisions, is unclear in the case of Fiji.

However, a vital question that remains is: will autonomy for health centres result in gains in health outcomes? There have been mixed results in countries where decentralisation has taken place. In Fiji, whilst an increase of $300 \%$ has been reported in the utilisation of health services at the health centre level, funding for ambulatory care has declined. ${ }^{71}$ The increase in utilisation at each health facility corresponds with a decrease in time spent with each user of general outpatient services. Whilst there are variations in utilisation and time spent on users between health facilities, the consistent decline in time spent with each user following decentralisation may suggest a decline in quality. However, this needs further examination. An important question is whether the shift from healthcare users accessing the hospitals directly, to health centres being their principal point of contact with the health system, has resulted in health gains or improvement in accessing healthcare. However, deconcentration, has allowed the central office to focus on the development of tertiary services at hospital level, a cornerstone in the argument for the $\mathrm{MoH}$ to roll-out this form of deconcentration to other divisions.

It is claimed that increasing decision space has numerous benefits. ${ }^{1,8,9}$ This paper has demonstrated that the level of decision space created following the decentralisation in the form of deconcentration has been minimal. With the aim of the deconcentration to improve access of users by bringing health services closer to them, creating decision space in the functions of service organisation, access rules and governance could facilitate the achievement of this goal. Future studies 
should focus on whether decision space is expanded as the Fijian health system continues to decentralise and if so, whether expected benefits follow. Further studies should also focus on whether decentralisation achieves its intended outcome of improving user's access to healthcare.

\section{Acknowledgements}

The Authors thank the staff of the Ministry of Health $(\mathrm{MoH})$, Fiji in providing information for this study.

\section{Ethical issues}

Ethical approval for the study, included in a broader study, was obtained from Human Participants Ethics Committee, The University of Auckland, Auckland, New Zealand [Approval \#8861, November 9, 2012] and the Fiji National Research Ethics Review Committee [Approval \#2013 06, May 17, 2013].

\section{Competing interests}

The authors declare that they have no competing interests.

\section{Authors' contributions}

All authors contributed to the paper. JM, NN, and TA were responsible for the study design. JM collected and analysed the data and drafted the paper. JM, $\mathrm{NN}$, and TA contributed to the revisions of the paper. JM, NN, and TA reviewed and edited the manuscript in its final form.

\section{References}

1. Mills A, Vaughan JP, Smith DL, Tabibzadeh I. Health System Decentralization: Concepts, Issues and Country Experience. Geneva: World Health Organisation; 1990.

2. Rondinelli D. Government decentralization in comparative perspective: theory and practice in developing countries. International Review of Administrative Sciences. 1980;47(2):133145. doi:10.1177/002085238004700205

3. Sen K, Koivusalo M. Health care reforms and developing countries - a criticial overview. Int J Health Plan Dev. 1998(13):199215. doi:10.1002/(sici)1099-1751(1998070)13:3\%3C199::aidhpm518\%3E3.3.co;2-t

4. Bossert T. Analyzing the decentralization of health systems in developing countries: decision space, innovation and performance. Soc Sci Med. 1998;47(10):1513-1527. doi:10.1016/s0277-9536(98)00234-2

5. World Health Organization (WHO). Declaration of Alma-Ata, 1978. Geneva: WHO; 2005.

6. Mosca I. Is decentralisation the real solution? A three country study. Health Policy. 2006;77(1):113-120. doi:10.1016/j. healthpol.2005.07.011

7. Peckham S, Exworthy M, Greener I, Powell M. Decentralizing health services: more local accountability or just more central control? Public Money \& Management. 2005;25(4):221-228. doi:10.1111/j.1467-9302.2005.00477.x

8. Regmi K. Decentralizing Health Services: A Global Prespective. New York: Springer; 2014

9. Saltman R, Bankauskaite V, Vrangbaek K, eds. Decentralization in Health Care: Strategies and Outcomes. Berkshire: Open University Press; 2007.

10. Rondinelli D, Nellis JR, Cheema GS. Decentralization in Developing Countries: A Review of Recent Experience. Washington DC: The World Bank; 1983.

11. Dubois HF, Fattore G. Definitions and typologies in public administration research: the case of decentralization. Int J Public Adm. 2009;32(8):704-727. doi:10.1080/01900690902908760

12. De Vries MS. The rise and fall of decentralization: a comparative analysis of arguments and practices in European countries. Eur J Polit Res. 2000;38(2):193-224. doi:10.1111/1475-6765.00532

13. Berman P, Bossert T. A decade of health sector reform in developing countries: what have we learned. DDM Report No. 81. Boston; 2000.

14. Bossert T, Chitah MB, Bowser D. Decentralization in Zambia: resource allocation and district performance. Health Policy Plan. 2003;18(4):357-369. doi:10.1093/heapol/czg044

15. Kolehmainen-Aitken RL. Decentralization and human resources: implications and impact. Human Resources for Health Development Journal. 1998;2(1):1-29.

16. Mills A. Decentralization and accountability in the health sector from an international perspective: what are the choices? Public Adm Dev. 1994;14(3):281-292. doi:10.1002/pad.4230140305

17. Bossert $\mathrm{T}$, Beauvais $\mathrm{J}$. Decentralization of health systems in Ghana, Zambia, Uganda and the Philippines: a comparative analysis of decision space. Health Policy Plan. 2002;17(1):1431. doi:10.1093/heapol/17.1.14

18. Bossert T, Larrañaga $O$, Giedion U, Arbelaez JJ, Bowser D. Decentralization and equity of resource allocation: evidence from Colombia and Chile. Bull World Health Organ. 2003;81(2):95100.

19. Eisenhardt KM. Agency theory: an assessment and review. Acad Manage Rev. 1989;14(1):57-74. doi:10.5465/amr.1989.4279003

20. Fiji Islands Bureau of Statistics. Fiji Facts and Figures as at 1st July 2010. http://www.statsfiji.gov.fj/Releases/FFF2010.pdf. Accessed November 27, 2014. Published 2010.

21. The Ministry of Health $(\mathrm{MoH})$. The Ministry of Health Annual Report 2013. Suva; 2014.

22. The Government of Fiji. Report of the Senate Select Committee of the Fiji Health Service (Parliamentary Paper No. 44 of 1997). Vol Parliamentary Paper No. 44 of 1997. Suva; 1997.

23. Coombe D. A review of the administrative aspects of the management of health services in Fiji. Suva; 1982.

24. Dunn I. Divisional Hospital Management. Suva; 1997.

25. The Government of Fiji. The Report of the Select Committee on the Fiji Health Service (Parliamentary Paper No. 28 of 1979). Suva; 1979.

26. The Ministry of National Planning. Roadmap for democracy and sustainable socio-economic development 2009-2014. Suva; 2009.

27. The Government of Fiji. People's charter for change, peace and progress. http://www.rfmf.mil.fj/Docs/finalcharter.pdf. Accessed October 16, 2014. Published 2008.

28. The Ministry of Health $(\mathrm{MoH})$. The Ministry of Health Annual Corporate Plan 2011. Suva; 2011.

29. The Ministry of Health $(\mathrm{MoH})$. The Ministry of Health Annual Corporate Plan 2010. Suva; 2010.

30. The Government of Fiji. The Economy and Efficiency Review of the Colonial War Memorial Hospital. Suva: The Auditor General; 1996.

31. The Ministry of Health $(\mathrm{MoH})$. Fiji Health Management Reform Project. Suva; 1999.

32. Rabukawaqa V. Health Sector reform in the Pacific: a Fijian divisional perspective. Papua New Guinea Medical Journal. 2006;49(3/4):93.

33. Rokovada L. Health sector reform and the health management reform project in Fiji. Papua New Guinea Medical Journal. 2006;49(3/4):87.

34. AUSHealth International. Fiji Health Management Reform Project Draft Annual Plan 2000-2001. Suva: AUSHealth International; 2000.

35. Ghai Y. Public Aministration and Management in Small States: Pacific Experiences. London: The Commonwealth Secretariat and The University of the South Pacific; 1990.

36. The Government of Fiji. Proposed Decentralisation of Health Services in the Republic of Fiji. Suva; 1990.

37. Roberts G, Irava W, Tuiketei T, et al. The Fiji Islands Health System Review. Geneva: WHO; 2011. 
38. The Ministry of Health $(\mathrm{MoH})$. The Ministry of Health Women Social Welfare and Poverty Alleviation Annual Report 2008. Suva; 2008.

39. The Ministry of Health (MoH). Cabinet Memorandum - Report of the Decentralisation of the General Outpatient Department (GOPD) Services. Suva; 2011.

40. The Ministry of Health $(\mathrm{MoH})$. Cabinet Decision No 21Decentralisation of the General Outpatient Services in Suva Subdivision. Suva; 2012.

41. The Ministry of Health $(\mathrm{MoH})$. Decentralisation Update As of April 2011. Suva: The Ministry of Health; 2011.

42. Shamim Z. Hospital Closes GOPD Services. The Fiji Times. 2011.

43. The Ministry of Health $(\mathrm{MoH})$. Decentralisation of the Outpatient Services from CWM Hospital to the Health Centres in the Suva Subdivision. Suva; 2010.

44. The Ministry of Health $(\mathrm{MoH})$. Equipment List for Suva Subdivision Health Centres. Suva; 2011.

45. The Ministry of Health $(\mathrm{MoH})$. Extension of Hours Report for Nuffield, Lami, Samabula Health Centre. Suva; 2010.

46. The Ministry of Health $(\mathrm{MoH})$. Resource Needs List for Health Centres in the Suva Subdivision. Suva; 2010.

47. Thomas Bossert, Mitchell A. Health sector decentralization and local decision-making: decision space, institutional capacities and accountability in Pakistan. Soc Sci Med. 2011;72(1):39-48. doi:10.1016/j.socscimed.2010.10.019

48. Bossert T, Bowser D, Amenyah J. Is Decentralization good for logistics systems? Evidence on essential medicine logistics in Ghana and Guatemala. Health Policy Plan. 2007;22(2):73-82. doi:10.1093/heapol/czl041

49. Bossert $T$, Larrañaga $O$, Meir FR. Decentralization of Health Systems in Latin America. Rev Panam Salud Publica. 2000;8(12):84-92.

50. The Ministry of Health $(\mathrm{MoH})$. Fiji Health Accounts: National Health Expenditure 2009-2010. Suva; 2011.

51. The Ministry of Health (MoH). Fiji Health Accounts 2007-2008. Suva; 2010.

52. The Ministry of Health (MoH). Fiji Health Accounts: National
Health Expenditure 2011-2012. Suva; 2013.

53. The Ministry of Health (MoH). Annual Corporate Plan 2014. Suva; 2014.

54. The Ministry of Health $(\mathrm{MoH})$. Ministry of Health Annual Report 2012. Suva; 2013.

55. The Ministry of Finance (MoF). Fiji Budget Estimates 2012. Suva; 2011.

56. The Ministry of Finance (MoF). Fiji Budget Estimates 2013. Suva; 2012.

57. The Ministry of Finance (MoF). Fiji Budget Estimates 2014. Suva; 2013.

58. Public Hospitals and Dispensaries Act, (1976).

59. Public Hospitals and Dispensaries (Amendment) Decree 2012 (Decree No. 36 of 2012), (2012).

60. Public Hospitals and Dispensaries (Amendment) Regulations 2012, Legal Notice No. 64, (2012).

61. The Ministry of Health $(\mathrm{MoH})$. The Ministry of Health Strategic Plan 2011-2015. Suva; 2011.

62. The Public Services Commission (PSC). Policy on Appointment of the Public Service. Suva; 2011.

63. The Public Services Commission (PSC). Policy on Staff Establishment of the Public Service. Suva; 2011.

64. The Public Services Commission (PSC). Terms and Conditions of Employment for Government Wage Earners. Suva; 2010.

65. The Ministry of Health $(\mathrm{MoH})$. Central Eastern Annual Report 2013. Suva; 2013.

66. The Ministry of Health $(\mathrm{MoH})$. Central Eastern Annual Report 2012. Suva; 2012.

67. The Ministry of Health (MoH). Central Eastern Annual Report 2011. Suva: $\mathrm{MoH} ; 2011$.

68. Pratap R. Hospitals Lack Basic Items. Fiji Broadcasting Service. 2014.

69. S. Tagilala \& Co. Ministry of Health - Fiji Retention Strategies to Minimise Skill Losses 2005 -2010. Suva: S. Tagilala \& Co; n.d.

70. Dewdney J. Health Workforce Plan Fiji 1997-2007. Sydney: WHO Regional Training Centre; 1997.

71. Chand S. Patient Load Increases. The Fiji Times. 2011. 